ventricular function after surgical correction of mitral regurgitation caused by leaflet prolapse. J Thorac Cardiovasc Surg. 2009;137:1071-6.

6. Suri RM, Schaff HV, Dearani JA, Sundt TM 3rd, Daly RC, Mullany CJ, et al. Determinants of early decline in ejection fraction after surgical correction of mitral regurgitation. J Thorac Cardiovasc Surg. 2008;136:442-7.

7. Tribouilloy C, Grigioni F, Avierinos JF, Barbieri A, Rusinaru D, Szymanski C, et al. Surviva implication of left ventricular end-systolic diameter in mitral regurgitation due to flail leaflets: a long-term follow-up multicenter study. J Am Coll Cardiol. 2009;54:1961-8.

8. Tribouilloy C, Rusinaru D, Grigioni F, Michelena HI, Vanoverschelde JL, Avierinos JF, et al. Long-term mortality associated with left ventricular dysfunction in mitral regurgitation due to flail leaflets: a multicenter analysis. Circ Cardiovasc Imaging. 2014;7:363-70.

9. Glower DD, Kar S, Trento A, Lim DS, Bajwa T, Quesada R, et al. Percutaneous mitral valve repair for mitral regurgitation in high-risk patients: results of the EVEREST II study. J Am Coll Cardiol. 2014;64:172-81.

10. Suri RM, Vanoverschelde JL, Grigioni F, Schaff HV Tribouilloy C, Avierinos JF, et al. Association between early surgical intervention vs watchfu waiting and outcomes for mitral regurgitation due to flail mitral valve leaflets. JAMA. 2013;310: 609-16.

http://dx.doi.org/10.1016/ j.jtcvs.2014.12.010

\section{SIZE MATTERS}

\section{To the Editor:}

I congratulate Oki and colleagues, ${ }^{1}$ who clearly demonstrated the benefit of combined single-scope endobronchial ultrasound (transbronchial; EBUS) and endoscopic ultrasound (transesophageal; EUS) staging relative to EBUS alone (sensitivity for mediastinal nodes, $73 \%$ vs $52 \%$ ). Since the Assessment of Surgical Staging Versus Endosonography (ASTER) trial $^{2}$ guidelines have stated that mediastinal nodal tissue staging should start with endosonography. ${ }^{3}$ Whether optimal endosonographic staging can be achieved by EBUS alone or whether the EBUS plus EUS combination is needed, however, is subject to debate. Although it is obvious that 2 tests increase the rate of detected nodal metastases relative to a single procedure, the routine addition of EUS performed with the EBUS scope is under discussion, with a recent study reporting little sensitivity benefit (increase from $82 \%$ to $85 \%$ ). ${ }^{4}$ An important message of the study of Oki and colleagues ${ }^{1}$ is that the sensitivity of EBUS alone in small nodes seems substantially lower than the sensitivity of EBUS reported in a recent guideline $(89 \%))^{3}$ It should be acknowledged that various of the initial EBUS studies reported outcomes of selected patients with either enlarged or fludeoxyglucoseavid nodes. These selected patients differ from consecutive patients in daily practice, who often have subcentimeter nodes, as in the study by Oki and colleagues. ${ }^{1}$ The sensitivity of EBUS in routine practice will thus most likely be lower than initially reported, especially when dealing with patients with small nodes.

In my experience, these subcentimeter nodes in the often affected stations 4L (paratracheal left) and 7 (subcarinal) can be very elegantly sampled by EUS-B. Oki and colleagues $^{1}$ clearly demonstrated that EUS-B has an added value to EBUS alone even if the same node had been sampled by EBUS before, particularly in the case of station 7 . This is an important take-home message: EUS-B not only has an added value in evaluating nodes located out of reach of EBUS but also in evaluating those within reach of EBUS that have been punctured before. An explanation for this finding might be the far easier sampling by the esophageal route because of the absence of cartilage rings and cough.

With regard to the performance of EUS-B, however, I wonder why all the patients in the study of Oki and colleagues $^{1}$ were turned from a supine to a left lateral position when switching from EBUS to EUS-B. The latter position is the classic approach for conventional EUS, but in my experience it is not necessary for an adequate mediastinal evaluation. Simply repositioning the EBUS scope from the trachea into the esophagus in single elegant movewithout turning the patient-further simplifies the combined EBUS and EUS-B procedure.

The study by Oki and colleagues ${ }^{1}$ underscores the importance of the EUS-B approach, showing a large diagnostic benefit by adding just 10 minutes of procedure time. It is now time for EUS-B implementation, with the mental switch for pulmonologists and surgeons to enter the esophagus probably being the largest barrier.

Jouke T. Annema, MD, PhD Department of Respiratory Medicine Academic Medical Center Amsterdam Amsterdam, The Netherlands

\section{References}

1. Oki M, Saka H, Ando M, Kitagawa C, Kogure Y, Seki Y. Endoscopic ultrasound-guided fine needle aspiration and endobronchial ultrasound-guided transbronchial needle aspiration: are two better than one in mediastinal staging of non-small cell lung cancer? J Thorac Cardiovasc Surg. 2014; 148:1169-77.

2. Annema JT, van Meerbeeck JP, Rintoul RC, Dooms C, Deschepper E, Dekkers OM, et al. Mediastinoscopy vs endosonography for mediastinal nodal staging of lung cancer: a randomized trial. JAMA. 2010;304:2245-52.

3. Silvestri GA, Gonzalez AV, Jantz MA, Margolis ML, Gould MK, Tanoue LT, et al. Methods for staging non-small cell lung cancer: diagnosis and management of lung cancer, 3rd ed: American College of Chest Physicians evidencebased clinical practice guidelines. Chest. 2013; 143(5 Suppl):e211S-50S.

4. Kang HJ, Hwangbo B, Lee GK, Nam BH, Lee HS, Kim MS, et al. EBUS-centred versus EUS-centred mediastinal staging in lung cancer: a randomised controlled trial. Thorax. 2014;69: 261-8.

5. Annema JT. When will we finally adopt endoscopic ultrasound? Chest. 2014;146:e117.

http://dx.doi.org/10.1016/ j.jtcvs.2014.11.050

\section{TWO TECHNIQUES ARE BETTER THAN ONE Reply to the Editor:}

We thank Dr Annema for his insightful comments regarding our study ${ }^{1}$ evaluating the roles of combined endobronchial ultrasound-guided transbronchial needle aspiration (EBUSTBNA) and transesophageal endoscopic ultrasound-guided fine-needle aspiration (EUS-FNA) with a single EBUS 
bronchoscope in the preoperative nodal staging of non-small cell lung cancer. In the study, ${ }^{1}$ we demonstrated that the sensitivity of combined EBUS-TBNA and EUS-FNA was significantly higher than that of each technique alone.

The usefulness of EBUS-TBNA for the mediastinal nodal staging of lung cancer is clear. The sensitivity of EBUS-TBNA alone has been reported $^{2}$ to be as high as $89 \%$, and so this technique alone seems to be good enough on the basis of the excellent initial results. However, many previous studies with excellent results have biases in patient selection. Some of them included only patients with a high pretest probability (eg, enlarged, positron emission tomography-positive lymph nodes) or excluded patients with lymph nodes that would not likely be accessed by EBUS. ${ }^{2,3}$

The sensitivity in our study, which included patients with normal-sized lymph nodes and inaccessible lymph nodes by EBUS, and excluded patients with bulky lymph nodes, is lower than that in the previous reports. Especially in patients with normal mediastinum on computed tomography and positron emission tomography, we encountered difficulty detecting mediastinal metastases by EBUS-TBNA. Similarly, some recent studies $^{4,5}$ have reported that the sensitivity of EBUS-TBNA in patients with radiologically normal mediastinum was lower than that found in previous studies. In particular, the study by Shingyoji and colleagues, ${ }^{5}$ reported that the sensitivity of EBUS-TBNA for nodal staging in patients with radiologically normal mediastium was $35 \%$.

As suggested by Dr Annema, stations $4 \mathrm{~L}$ and 7 can be easily sampled by EUS-FNA. In our study, ${ }^{1}$ positive results from these lymph nodes, especially normal-sized lymph nodes, could be achieved only by EUS-FNA in some cases. We performed 2 punctures for each lesion using each procedure, and the positive specimen might have been sampled at the 3rd or 4th puncture, which was performed through the esophagus. However, as suggested by Dr Annema, we believe that the better ultrasonic visibility, accessibility, and tolerability of EUS-FNA contributed to the increased yield. EUSFNA plays a complementary role to that of EBUS-TBNA, for not only inaccessible lesions with EBUS, including stations 8,9 , and 5 , but also accessible ones, including stations $4 \mathrm{~L}$ and 7.

We learned the EUS-FNA procedure from a gastroenterologist, ${ }^{6}$ and have performed the procedure at the left lateral position, which is the traditional EUS-FNA position, with an EUS endoscope for preventing gastroesophageal reflux and cough during the procedure. Other investigators $^{7}$ successfully performed this procedure with the supine position. Although the reports ${ }^{1,6,7}$ on the usefulness of EUS-FNA using an EBUS bronchoscope have gradually increased, the details of its clinical implementation, such as techniques, indications, and method of training, remain unknown. We must further investigate this useful procedure, which can be performed with an EBUS bronchoscope by pulmonologists and/or thoracic surgeons.

Masahide Oki, MD

Hideo Saka, MD

From the Department of Respiratory Medicine

Nagoya Medical Center Nagoya, Japan

\section{References}

1. Oki M, Saka H, Ando M, Kitagawa C, Kogure Y, Seki Y. Endoscopic ultrasound-guided fine needle aspiration and endobronchial ultrasound-guided transbronchial needle aspiration: Are two better than one in mediastinal staging of non-small cell lung cancer? J Thorac Cardiovasc Surg. 2014; 148:1169-77.

2. Silvestri GA, Gonzalez AV, Jantz MA, Margolis ML, Gould MK, Tanoue LT, et al. Methods for staging non-small cell lung cancer: Diagnosis and management of lung cancer, 3rd ed: American College of Chest Physicians evidence-based clinical practice guidelines. Chest. 2013;143(5 Suppl):e211S-50S.
3. Klapper JA, Denlinger CE. Pathologic staging of the mediastinum: when and how? J Thorac Cardiovasc Surg. 2014;148:1177-8.

4. Szlubowski A, Zieliński M, Soja J, Annema JT, Sośnicki W, Jakubiak M, et al. A combined approach of endobronchial and endoscopic ultrasound-guided needle aspiration in the radiologically normal mediastinum in non-small-cell lung cancer staging - a prospective trial. Eur $J$ Cardiothorac Surg. 2010;37:1175-9.

5. Shingyoji M, Nakajima T, Yoshino M, Yoshida Y, Ashinuma H, Itakura M, et al. Endobronchial ultrasonography for positron emission tomography and computed tomography-negative lymph node staging in non-small cell lung cancer. Ann Thorac Surg. 2014;98:1762-7.

6. Oki M, Saka H, Ando M, Tsuboi R, Nakahata M, Oka S, et al. Transbronchial versus transesophageal needle aspiration using an ultrasound bronchoscope for the diagnosis of mediastinal lesions: a randomized study. Chest. 2014 [Epub ahead of print].

7. Hwangbo B, Lee GK, Lee HS, Lim KY, Lee SH Kim HY, et al. Transbronchial and transesophageal fine-needle aspiration using an ultrasound bronchoscope in mediastinal staging of potentially operable lung cancer. Chest. 2010;138:795-802.

http://dx.doi.org/10.1016/ j.jtcvs.2014.12.010

\section{HIGH ACTIVATED CLOTTING TIME, OR VENOUS GRAFT, OR OFF-PUMP CORONARY ARTERY BYPASS GRAFTING? TOO EARLY TO CALL OFF THE PARTY!}

\section{To the Editor:}

I congratulate Houlind and colleagues $^{1}$ for a well-planned study between coronary artery bypass grafting $(\mathrm{CABG})$ performed off pump (OPCAB) versus conventional CABG. It is interesting to note that in this study the patency rates of the internal thoracic artery (ITA) grafts were the same for both groups, with $74 \%$ of the occlusions seen at the site not different between the 2 techniques. ${ }^{2}$ It is well known in the real world that the harvesting of venous grafts and the top ends are often left to the junior colleagues. Moreover, venous grafts are prone to kinking with even a little excess length, whereas arterial grafts are more forgiving of excess length.

It is noteworthy that activated clotting time (ACT) was maintained at longer than 400 seconds and that 